\title{
Point Mutation in a Leucine-rich Repeat of Platelet Glycoprotein Ib $\alpha$ Resulting in the Bernard-Soulier Syndrome
}

\author{
Jerry Ware, * Susan R. Russell, * Patrizia Marchese, " Mitsuru Murata, * Mario Mazzucato, ${ }^{\star}$ Luigi De Marco, ${ }^{*}$ \\ and Zaverio M. Ruggeri* \\ ${ }^{*}$ Roon Research Laboratory for Arteriosclerosis and Thrombosis, Division of Experimental Hemostasis and Thrombosis, Department of \\ Molecular and Experimental Medicine, and Committee on Vascular Biology, The Scripps Research Institute, La Jolla, California 92037; \\ and ${ }^{\ddagger}$ Centro Trasfusionale e Chimica Clinica, C.R.O. 33081 Aviano, Pordenone, Italy
}

\begin{abstract}
Leucine-rich repeats are a conserved structural motif, of yet undefined significance, found in a group of proteins from different species. Among these are the four components of the human platelet glycoprotein Ib-IX-V complex, a membrane receptor that performs an essential role in the thrombogenic function of platelets by interacting with the adhesive protein, von Willebrand factor. We have found that a single amino acid substitution (Ala ${ }^{156} \rightarrow \mathrm{Val}$ ) within one of the six leucine-rich repeats in the $\alpha$-subunit of glycoprotein Ib results in a variant form of the congenital bleeding disorder, Bernard-Soulier syndrome, characterized by giant dysfunctional platelets. Genetic studies of the propositus and his family members were complemented by immunological and functional analysis of expressed recombinant GP Ib $\alpha$ fragments to demonstrate that the observed mutation is the cause of defective von Willebrand factor binding. These studies define the molecular basis of the Bernard-Soulier syndrome within this family and demonstrate that structural integrity of a leucine-rich repeat is necessary for normal function of the glycoprotein Ib-IX-V receptor complex and, possibly, for normal platelet morphology. (J. Clin. Invest. 1993. 92:1213-1220.) Key words: thrombosis - bleeding disorder • von Willebrand factor • platelet adhesion • giant platelets
\end{abstract}

\section{Introduction}

The Bernard-Soulier syndrome $(1,2)$ is a congenital bleeding disorder characterized by giant platelets with an absent or dysfunctional platelet membrane receptor, the glycoprotein (GP) ${ }^{1}$ Ib-IX-V complex (3). At sites of vascular injury, the GP Ib $\alpha$ component of this receptor interacts with the adhesive protein, von Willebrand factor ( $\mathrm{vWF}$ ), to support platelet adhesion and initiate thrombus formation (3). The GP Ib-IX-V receptor is assembled from four distinct gene products into a hetero-oligo-

Address correspondence to Dr. Zaverio M. Ruggeri, The Scripps Research Institute, SBR 8, 10666 North Torrey Pines Road, La Jolla, CA 92037.

Received for publication 20 August 1992 and in revised form 21 April 1993.

1. Abbreviations used in this paper: $\mathrm{CHO}$, Chinese hamster ovary; GP, platelet membrane glycoprotein; PCR, polymerase chain reaction.

\section{J. Clin. Invest.}

(C) The American Society for Clinical Investigation, Inc.

0021-9738/93/09/1213/08 \$2.00

Volume 92, September 1993, 1213-1220 meric complex composed of the disulfide-linked $\alpha-(4,5)$ and $\beta$-subunits (6) of GP Ib associated in a noncovalent manner with GP IX (7) and GP V $(8,9)$. Most cases of Bernard-Soulier syndrome may be caused by a genetic defect within one of the subunits, preventing a coordinated assembly of the complex and, thus, membrane expression (10). The validity of this concept has been proven in a family bearing a nonsense mutation in the GP Ib $\alpha$ gene (11) and by the coordinated expression of a recombinant GP Ib-IX complex on the surface of heterologous cells (12).

In contrast to the classical form of the disease, a previously characterized variant of Bernard-Soulier syndrome, designated type Bolzano, was found to express a dysfunctional GP Ib-IX$\mathrm{V}$ complex on the surface of giant platelets that lacked the ability to bind vWF (13). In this report we demonstrate that the latter abnormality is caused by an $\mathrm{Ala}^{156} \rightarrow$ Val substitution within the conserved leucine-rich motif present in GP Ib $\alpha$ (14). Expression of an isolated recombinant GP Ib $\alpha$ analogue containing the mutation resulted in a structural and functional abnormality equivalent to that associated with type Bolzano platelets. These findings establish that the leucine-rich motif is an important structural element in the GP Ib-IX-V complex and is required for normal platelet activity in hemostasis.

\section{Methods}

Bernard-Soulier syndrome, type Bolzano. The propositus was previously described as a typical case of Bernard-Soulier syndrome, with giant platelets exhibiting a markedly decreased vWF-binding capacity $(13,15)$. Detailed immunochemical studies revealed also a major structural abnormality of GP Ib $\alpha$ characterized by the absence of conformation-dependent epitopes recognized by specific monoclonal antibodies (13).

Genetic studies. Blood samples were obtained from the propositus, other family members, and normal blood donors recruited through the General Clinical Research Center of Scripps Clinic. All individuals were informed of the purpose of these studies and gave their consent according to the Declaration of Helsinki. Genomic DNA was isolated from peripheral lymphocytes using standard procedures (16). Bacteriophage clones containing the propositus' GP Ib $\alpha$ gene were isolated from a library of EcoRI restriction fragments propagated in the cloning vector $\lambda$ ZAP (Stratagene Cloning Systems, La Jolla, CA) (17). Purified bacteriophages were characterized by restriction enzyme mapping, and this analysis identified an EcoRI fragment of $\sim 6,000$ bp in length containing the entire GP Ib $\alpha$ gene; this fragment was subsequently subcloned into $\mathrm{pBS} / \mathrm{SK}^{-}$for DNA sequence analysis. The coding sequence for the propositus' GP Ib $\alpha$ was also amplified by polymerase chain reactions (PCR) (18) into a series of overlapping fragments that generated a composite array of the GP Ib $\alpha$ gene. PCR fragments were subcloned into the M13 vector before DNA sequence analysis. The latter was performed using GP Ib $\alpha$-specific oligonucleotides synthesized according to published GP Ib $\alpha$ sequences $(5,19)$. Southern transfer and hybridization were performed essentially as described (17). 
Two missense mutations corresponding to residues 145 and 156 of GP Ib $\alpha$ were identified during the course of these studies. A 591-bp fragment containing the coding sequence for GP Ib $\alpha$ residues 106-302 (residue numbers are referenced from $\mathrm{His}^{1}$ of mature $\mathrm{GP} \mathrm{Ib} \alpha$ ) was generated by PCR and used for the characterization of the two mutations. The oligonucleotide primers used in the PCR contained nucleotides $899-919$ and $1470-1489$, as numbered in the published sequence (19).

Monoclonal and polyclonal antibodies. The production and characterization of the anti-GP Ib $\alpha$ monoclonal antibodies used in these studies have been described elsewhere (20-22). Antibody LJ-Ib $\alpha 1$ recognizes an epitope located within residues 1-237 and reacts with SDSdenatured and reduced GP Ib $\alpha$ antigen. Antibodies LJ-Ib1, LJ-P3, and LJ-P19 react with epitopes that are destroyed by treatment with SDS and are located in an amino-terminal 45-kD tryptic fragment of GP Ib $\alpha$ composed of residues 1-293. A rabbit polyclonal antibody was generated using a synthetic peptide composed of GP Ib $\alpha$ residues Gly ${ }^{271}-G^{285}$.

Expression of recombinant GP Ib $\alpha$ fragments. The characterization of a recombinant plasmid synthesizing a functional amino-terminal domain of GP Ib $\alpha$ has been described in detail elsewhere (22). Briefly, a mammalian cell expression plasmid was constructed from a fragment of the GP Ib $\alpha$ gene (coding for signal peptide and mature residues $\mathrm{His}^{1}-\mathrm{Ala}^{302}$ ) synthesized in a PCR that added BamHI restriction sites on the ends of the amplified fragment. The amplified GP Ib $\alpha$ fragment was cloned into M13mp19 as a BamHI fragment and sequenced to verify that no spontaneous mutations had arisen during the PCR. The GP Ib $\alpha$ insert was removed from the M13 construct by digestion with EcoRI and XbaI and cloned into the same restriction sites of the polylinker region of $\mathrm{PBS} / \mathrm{KS}^{-}$(Stratagene). As a result of cloning into $\mathrm{PBS} / \mathrm{KS}^{-}$, restriction sites for Xhol ( $5^{\prime}$ to the GP Ib $\alpha$ initiating Met codon) and NotI ( $3^{\prime}$ to the $\mathrm{Ala}^{302}$ codon) were acquired from the polylinker region and were used to clone the fragment into the mammalian cell expression plasmid, pCDM8 ${ }^{\text {neo }}$. The latter is identical to pCDM8 (23) except that it contains a neomycin gene for conferring resistance to the aminoglycoside antibiotic, G418 or Geneticin (Sigma Chemical Co., St. Louis, MO).

Mutations within the expression plasmid were constructed using mutagenic oligonucleotides and site-directed mutagenesis on uracilcontaining templates of the original M13 construct (24). After mutagenesis and subcloning into $\mathrm{PBS} / \mathrm{KS}^{-}$(described above), the mutant GP Ib $\alpha$ coding regions were completely sequenced to ensure that no additional mutagenic errors had occurred and then were cloned into the $\mathrm{pCDM} 8^{\text {neo }}$ expression plasmid.

Chinese hamster ovary (CHO-K1) cells were maintained in 5\% $\mathrm{CO}_{2}$ and grown in DME supplemented with $10 \%$ fetal calf serum ( $10 \%$ DME), $0.5 \mathrm{mM}$ nonessential amino acids, and $2 \mathrm{mM}$ L-glutamine (Whittaker Bioproducts, Walkersville, MD). DNA (10 $\mu \mathrm{g}$ per dish) was introduced into cells (subcultured at a density of $1.5 \times 10^{5}$ per 60-mm dish $24 \mathrm{~h}$ before transfection) using a calcium phosphate-mediated transfection procedure (25); cells were then maintained in 10\%-DME.

After transformation of CHO-K1 cells with each plasmid, cell lines secreting the recombinant GP Ib $\alpha$ fragments were identified in preliminary experiments by evaluating immunoreactivity with the anti-GP Ib $\alpha$ monoclonal antibody LJ-Ib $\alpha 1$. Subsequent screening was performed with the rabbit polyclonal antibody recognizing a GP Ib $\alpha$ epitope within Gly $^{271}-$ Glu $^{285}$; this linear epitope was assumed to be equally expressed in all the recombinant fragments regardless of the mutations at positions 145 and 156 . This analysis allowed comparable amounts of each recombinant fragment to be tested for immunoreactivity with the conformation-dependent anti-GP Ib $\alpha$ monoclonal antibodies LJ-Ib1, LJ-P3, and LJ-P19. For the detection of recombinant GP $\mathrm{Ib} \alpha$ antigen, a confluent flask of cells was cultured in the absence of fetal calf serum $(24 \mathrm{~h})$ and harvested for immunoblotting. The dot-blot technique used to evaluate the immunochemical reactivity of recombinant fragments has been described in detail elsewhere (22). In brief, proteins in the culture medium were immobilized onto nitrocellulose membranes by filtration, reacted with the appropriate specific anti- body, and detected by autoradiography after incubation with ${ }^{125} \mathrm{I}$-labeled rabbit anti-mouse IgG or ${ }^{125}$ I-labeled goat anti-rabbit IgG (22).

$v W F$ binding to immobilized recombinant fragments. The method used for this assay has been described in detail elsewhere (22). All reagents were filtered (in $\sim 5 \mathrm{~min}$ for each step) through a nitrocellulose membrane (0.45- $\mu \mathrm{m}$ pore size; Bio-Rad Laboratories, Hercules, CA ) using a peristaltic pump applied to a device that delimits a circular area of application (22). All the steps of this assay were performed at room temperature $\left(22-25^{\circ} \mathrm{C}\right)$. Serum-free culture media from different cell lines were either diluted with the appropriate amount of serumfree medium from nontransfected CHO-K1 cells or used in volumes (30-400 $\mu \mathrm{l}$ ) inversely proportional to the content of recombinant protein so that, in either case, comparable amounts of GP Ib $\alpha$ fragment were immobilized onto the nitrocellulose membrane. The amount of each mutant fragment used in the binding assay was nonlimiting, such that doubling it caused $<10 \%$ increase in vWF binding. After binding the medium from the appropriate cell line, the membrane was blocked with three washes ( $200 \mu \mathrm{l}$ each) of a solution containing $20 \mathrm{mM}$ Hepes and $150 \mathrm{mM} \mathrm{NaCl}, \mathrm{pH} 7.4$ (Hepes buffer), with $1 \%$ bovine serum albumin (fraction V; Calbiochem Corp., La Jolla, CA) and $1 \%$ bovine $\gamma$-globulin (prepared from plasma, $99 \%$ electrophoretic purity; Sigma Chemical Co.). After blocking, $50 \mu \mathrm{l}$ of ${ }^{125} \mathrm{I}$-labeled vWF, preincubated for $30 \mathrm{~min}$ with either botrocetin or ristocetin as modulators of binding (22), was filtered through the nitrocellulose membrane. The specific activity of the different preparations of ${ }^{125} \mathrm{I}$-vWF used varied between 13 and $140 \mu \mathrm{Ci} / \mathrm{mg}$. Ristocetin (Sigma Chemical Co.) was used at the final concentration of $1 \mathrm{mg} / \mathrm{ml}$; botrocetin (two-chain form) was purified as previously described in detail $(26,27)$ from the crude venom of Bothrops jararaca (Sigma Chemical Co.) and was used at the final concentration of $10 \mu \mathrm{g} / \mathrm{ml}$. When indicated, appropriate anti-GP Ib $\alpha$ monoclonal antibodies (the combination of LJ-Ibl and LJ-P19, 100 $\mu \mathrm{g} / \mathrm{ml}$ each ) were added to these mixtures before filtering through the nitrocellulose; a solution of the same antibodies was also filtered through the membrane before application of the vWF-containing mixture. After two additional washes in the blocking solution, the membrane was dried, the portion of the membrane corresponding to each application well was cut out, and the bound radioactivity determined in a $\gamma$-scintillation spectrometer. In the assays using the modulator ristocetin, the latter was also present in the final washing fluid at the same concentration used during the incubation with vWF. It is important to note that the addition of bovine $\gamma$-globulin to the solution used to block the nitrocellulose membrane proved essential to reduce the level of nonspecific binding, particularly when ristocetin was utilized as modulator. Binding was considered nonspecific when it occurred in the absence of recombinant GP Ib $\alpha$ fragment and/or was not inhibited by appropriate anti-GP Ib $\alpha$ monoclonal antibodies. Indeed, in several experiments performed without the use of $\gamma$-globulin in the blocking solution, we found variable nonspecific vWF binding to one or more component present also in nontransfected $\mathrm{CHO}-\mathrm{K} 1$ cell culture media. In total, of nine different control media tested for apparent vWF binding in the presence of ristocetin, only three exhibited values corresponding to background; four exhibited apparent binding that was $\geq 50 \%$, and two $>100 \%$ of that measured with the medium containing normal GP Ib $\alpha$ fragment. The same variable level of vWF binding was observed with fragments containing the $\mathrm{Ala}^{156} \rightarrow$ Val mutation; in either case, however, this nonspecific binding was essentially abolished when the nitrocellulose membrane was blocked with the solution containing bovine $\gamma$-globulin (see Results). Use of the latter, therefore, represents a crucial modification of the method previously described to measure vWF binding to recombinant GP Ib $\alpha$ fragments (22).

\section{Results}

Characterization of the GP Iba gene associated with the Bernard-Soulier syndrome, type Bolzano phenotype. The structural GP Ib $\alpha$ defect in platelets from the propositus with the type Bolzano phenotype was previously demonstrated by the 
A.

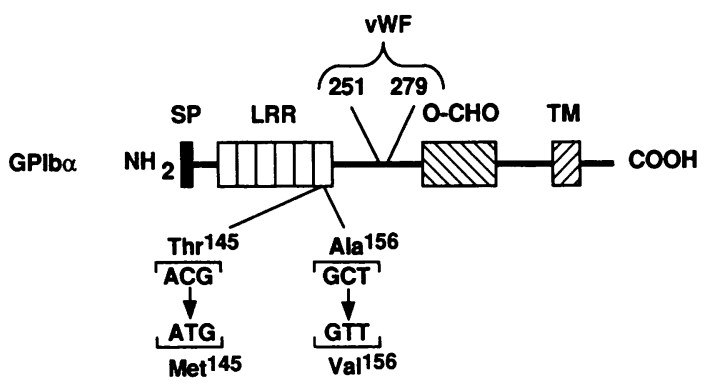

B.
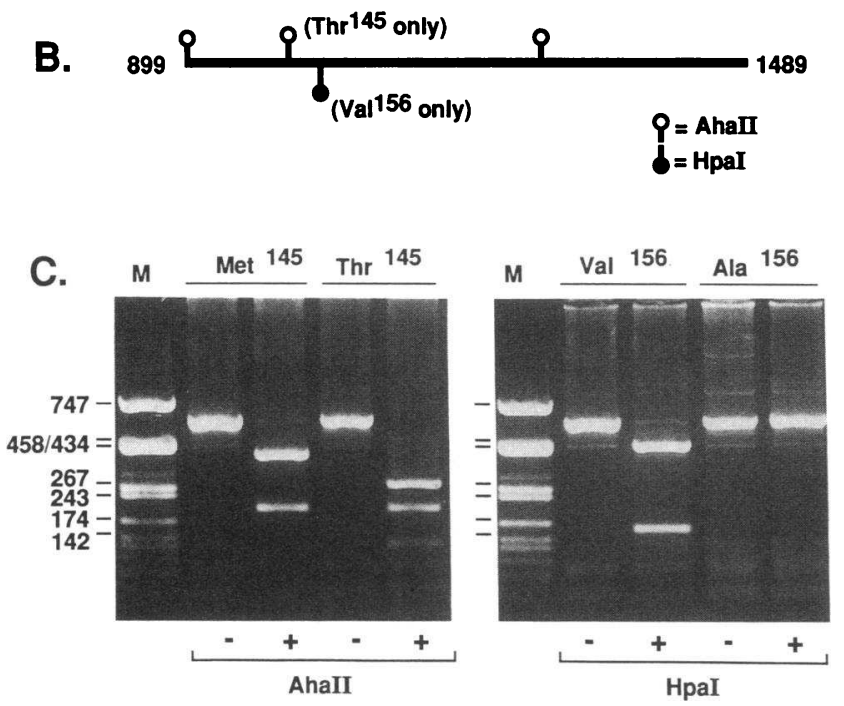

Figure 1. Primary structure of the GP Ib $\alpha$ protein, PCR strategy and restriction enzyme analyses. $(A)$ The precursor $\alpha$-subunit of GP Ib consists of a signal peptide (SP) and a 610-residue polypeptide both encoded within a single exon (19). The mature GP Ib $\alpha$ subunit contains six repeats of a leucine-rich motif (LRR) (residues 36-176), a binding site for von Willebrand factor (vWF), a carbohydrate-rich region $(\mathrm{O}-\mathrm{CHO})$, a transmembrane domain (TM), and an intracytoplasmic carboxyl-terminal tail $(4,5)$. As compared with the published GP Ib $\alpha$ gene sequences, genetic analysis of the propositus identified $\mathrm{Thr}^{145} \rightarrow$ Met and Ala ${ }^{156} \rightarrow$ Val codon substitutions, which abolish an Ahall restriction site and create a $\mathrm{Hpal}$ restriction site, respectively. This is documented in $B$ and $C$ by restriction enzyme digestion of a 591-bp fragment generated by PCR using the propositus' genomic DNA ( $\mathrm{Met}^{145} / \mathrm{Val}^{156}$ ) and DNA from a normal control $\left(\mathrm{Thr}^{145} / \mathrm{Ala}^{156}\right)$. The characterization of genomic DNA samples revealed that the $\mathrm{Thr}^{145} \rightarrow$ Met codon substitution is a naturally occurring dimorphism that produces restriction fragments of 271,201 , and $116 \mathrm{bp}$ for a $\mathrm{Thr}^{145}$-containing allele, or fragments of 387 and $201 \mathrm{bp}$ for a Met ${ }^{145}$-containing allele. A 591-bp fragment containing a Val ${ }^{156}$ codon produces fragments of 439 and $152 \mathrm{bp}$ after digestion with HpaI. Agarose electrophoresis of the amplified 591-bp fragment is shown either before $(-)$ or after $(+)$ digestion with the relevant restriction enzyme. Molecular weight standards (M) are indicated in base pairs.

abnormal interaction with specific monoclonal antibodies (13). Thus, to define the molecular basis of this variant form of Bernard-Soulier syndrome, we aimed our studies at a characterization of the gene encoding the $\alpha$-chain of GP Ib. Nucleotide sequence analysis was obtained from restriction enzyme fragments of bacteriophage $\lambda$ clones containing a complete copy of the propositus' GP Ib $\alpha$ gene as well as from DNA sequence analysis of PCR-generated fragments. Two $C$ to $T$ missense mutations were found on a continuous fragment derived from the GP Ib $\alpha$ gene of the propositus, indicating that both were present on the same allele: the codon for $\mathrm{Thr}^{145}$ (ACG) was changed to Met (ATG), and the codon for Ala ${ }^{156}$ (GCT) was changed to Val (GTT). DNA analysis by restriction enzyme digestion demonstrated that the propositus was homozygous for the two mutations (Fig. 1), whereas his parents were both heterozygous with cosegregation of the $\mathrm{Met}^{145}$ and $\mathrm{Val}^{156} \mathrm{co-}$ dons (not shown). The $\mathrm{Thr}^{145} \rightarrow$ Met mutation was subsequently determined to be a genetic dimorphism found in the normal population with an allele frequency of $11 \%(n=122)$ $(28,29)$; the Ala ${ }^{156} \rightarrow$ Val mutation, in contrast, was not detected in DNA fragments generated from normal individuals. The propositus was also homozygous, and both his parents were heterozygous, for a triplication of 39 nucleotides encoding residues 399-411 (Fig. 2). This is another GP Ib $\alpha$ polymorphism, described also by others (30), that in our studies was found to occur with an allele frequency of $13 \%(n=24)$.

Immunologic consequences of the $\alpha$-subunit missense mutations. We have previously shown that the amino-terminal domain of GP Ib $\alpha$ is structurally and functionally mimicked by a 302-residue recombinant fragment that can be independently expressed and secreted as a soluble species from $\mathrm{CHO}-\mathrm{K} 1$ cells (22). The expressed normal fragment is recognized by a panel of conformation-specific anti-GP Ib $\alpha$ monoclonal antibodies,
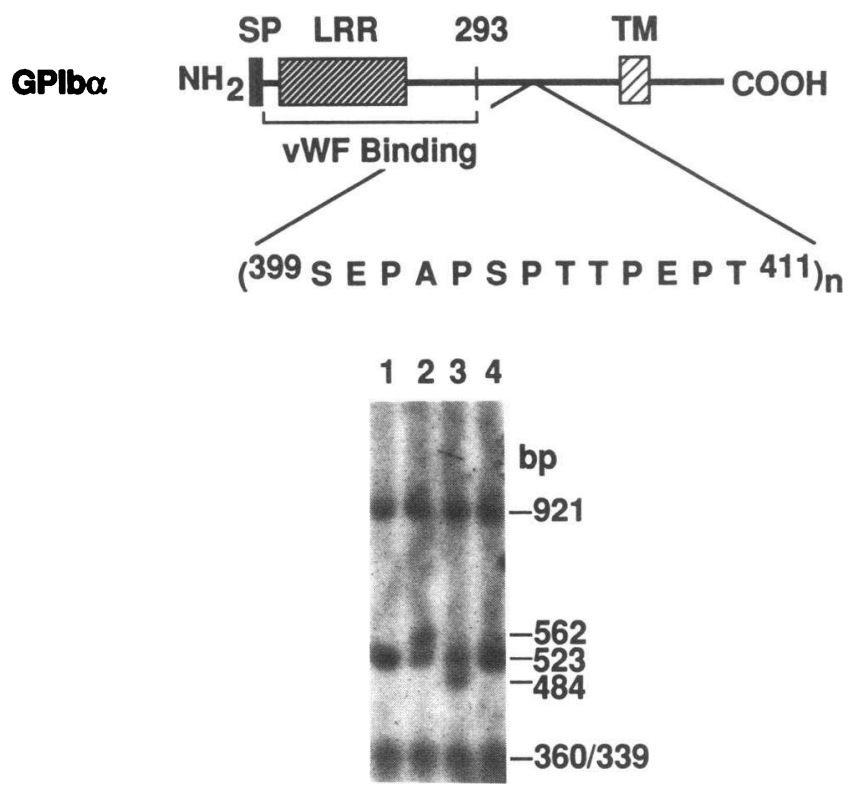

Figure 2. Southern blot analysis of a hypervariable motif within the extracytoplasmic carbohydrate-rich domain of GP Ib $\alpha$. Genomic DNA from normal individuals was digested with Avall and electrophoresed through a $1 \%$ agarose gel. The DNA was transferred to nitrocellulose via the Southern procedure and hybridized to a radiolabeled DNA fragment containing the entire coding sequence of GP Ib $\alpha$. The autoradiograph illustrates a single band of $921 \mathrm{bp}$ and a doublet of 360 and $339 \mathrm{bp}$ identical in all samples. In contrast, the hypervariable region corresponding to the polymorphic motif encoding GP $\mathrm{Ib} \alpha$ residues $\mathrm{Ser}^{399}-\mathrm{Thr}^{411}$ produces fragments ranging in size from 484 to 562 bp, as shown by the four different DNA samples from normal individuals. A triplication of this 13-residue sequence was originally found in the propositus' DNA, corresponding to the 562-bp fragment seen in the normal sample in lane 2 . The DNA samples shown in lanes 1 and 4 contain homozygous alleles for the 523-bp fragment; in lane 2, heterozygous alleles with the 562- and 523-bp fragments; and in lane 3, heterozygous alleles with the 523- and 484bp fragments. 


\section{Culture Medium}

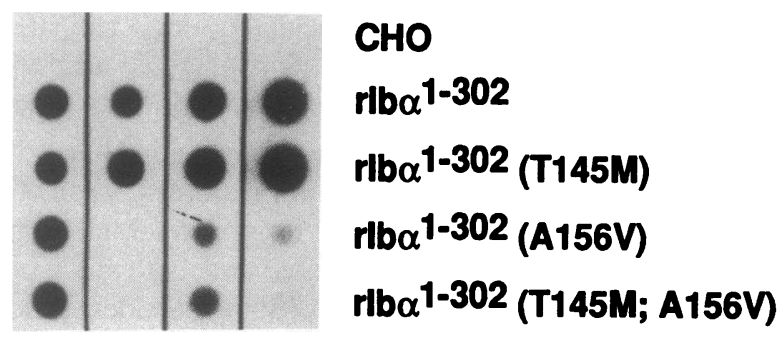

Figure 3. Epitope analysis of recombinant GP Ib $\alpha$ fragments by nondenaturing dot blot. Proteins in culture media were immobilized onto a nitrocellulose membrane; the latter was then saturated with a blocking solution and incubated with the appropriate mouse monoclonal antibody; positive reactivity was detected by incubation with ${ }^{125}$ I-labeled rabbit anti-mouse IgG and autoradiography. A panel of anti-GP Ib $\alpha$ monoclonal antibodies was tested for immunoreactivity with culture media obtained from nontransfected CHO-K1 cells (CHO); cells secreting a recombinant fragment with the more common $\left(\mathrm{Thr}^{145}\right)$ GP Ib $\alpha$ sequence, $r \mathrm{Ib} \alpha^{1-302}$; cells secreting the alternative $\mathrm{Met}^{145}$ dimorphic residue, $r \mathrm{Ib} \alpha^{1-302}(\mathrm{~T} 145 \mathrm{M})$; cells secreting the $\mathrm{Ala}^{156} \rightarrow$ Val substitution, $r \mathrm{Ib} \alpha^{1-302}(\mathrm{~A} 156 \mathrm{~V})$; cells secreting both the $\mathrm{Thr}^{145} \rightarrow$ Met and $\mathrm{Ala}^{156} \rightarrow$ Val substitution, $r \mathrm{Ib} \alpha^{1-302}$ (T145M;A156V). The monoclonal antibody LJ-Ib $\alpha 1$ recognizes an epitope present on reduced and denatured platelet GP Ib $\alpha$; LJ-Ib1, LJ-P3, and LJ-P19 each recognize epitopes that are destroyed by denaturation. The $\mathrm{LJ}-\mathrm{Ibl}$ epitope was previously reported to be abnormal on the propositus' platelets (13), as it is in the mutant recombinant fragments containing $\mathrm{Val}^{156}$; in contrast, the $\mathrm{LJ}-\mathrm{Ib} \alpha 1$ epitope is normal in all the fragments. LJ-P19 is a new monoclonal antibody recognizing a distinct conformation-dependent epitope in the amino-terminal domain of GP Ib $\alpha$ and confirms the results obtained with LJ-Ib1 and LJ-P3.

each reacting with a distinct epitope within the amino terminus of the molecule (22). The epitope of one of these antibodies, designated LJ-Ib1, was previously found to be typically absent in platelets from the type Bolzano propositus (13). Therefore, to evaluate the immunological consequences of the identified mutations, we expressed fragments bearing the dimorphism $\left(\mathrm{Thr}^{145} \rightarrow \mathrm{Met}\right)$ and the unique point mutation identified in the Bernard-Soulier variant ( $\mathrm{Ala}^{156} \rightarrow \mathrm{Val}$ ) either independently or in association (the latter representing the genotype of the propositus) and compared their immunoreactivity to that of the GP Ib $\alpha$ fragment with normal sequence. Like platelets from the propositus (13), the GP Ib $\alpha$ fragment bearing the $\mathrm{Thr}^{145} \rightarrow$ Met and Ala ${ }^{156} \rightarrow$ Val mutations had markedly decreased reactivity with $\mathrm{LJ}$-Ib1 and other conformation-dependent anti-GP Ib monoclonal antibodies (Fig. 3). The fragment bearing the single $\mathrm{Ala}^{156} \rightarrow$ Val mutation also demonstrated a similar abnormal reactivity, but a fragment with the single $\mathrm{Thr}^{145} \rightarrow$ Met mutation reacted normally (Fig. 3). This demonstrates that the $\mathrm{Ala}^{156} \rightarrow \mathrm{Val}$ mutation is responsible for the alteration in antibody recognition associated with the propositus' abnormal GP Ib-IX-V complex on platelets, regardless of the dimorphic residue at position 145. All mutant fragments reacted equally well with the conformation-independent antibody, $\mathrm{LJ}-\mathrm{Ib} \alpha 1$, after reduction of intramolecular disulfide bonds (Fig. 3); the latter, then, could be used to demonstrate the presence of immunoreactive GP Ib $\alpha$-related protein in different culture media.

Functional consequences of the $\alpha$-subunit missense mutations. In a previous publication we have proposed the concept that the vWF-binding function of the platelet GP Ib-IX-V complex can be recapitulated in the soluble recombinant GP $\mathrm{Ib} \alpha$ fragment containing residues 1-302 (22). We based our conclusions on the following observations: $(a)$ the binding of soluble vWF to immobilized recombinant fragment as well as to the intact GP Ib-IX-V receptor complex on platelets requires the presence of a modulator, either ristocetin or botrocetin; $(b)$ the binding of purified vWF to immobilized recombinant fragment can be inhibited with the same monoclonal antibodies that inhibit binding to the GP Ib-IX-V complex; and (c) vWF binding to immobilized recombinant fragment and intact GP Ib-IX-V complex on platelets exhibits essentially the same apparent affinity (22). In agreement with this concept, expression of the mutation identified in the type Bolzano BernardSoulier variant resulted in a dysfunctional recombinant fragment lacking vWF-binding activity, similar to the abnormality observed with intact platelets from the propositus (13). Indeed, using either ristocetin or botrocetin as modulators of vWF binding, it was apparent that the GP Ib $\alpha$ fragment bearing the $\mathrm{Thr}^{145} \rightarrow$ Met dimorphic substitution and the $\mathrm{Ala}^{156} \rightarrow \mathrm{Val}$ mutation (thus, with sequence identical to GP Ib $\alpha$ in the propositus) had negligible vWF binding function, not distinguish-
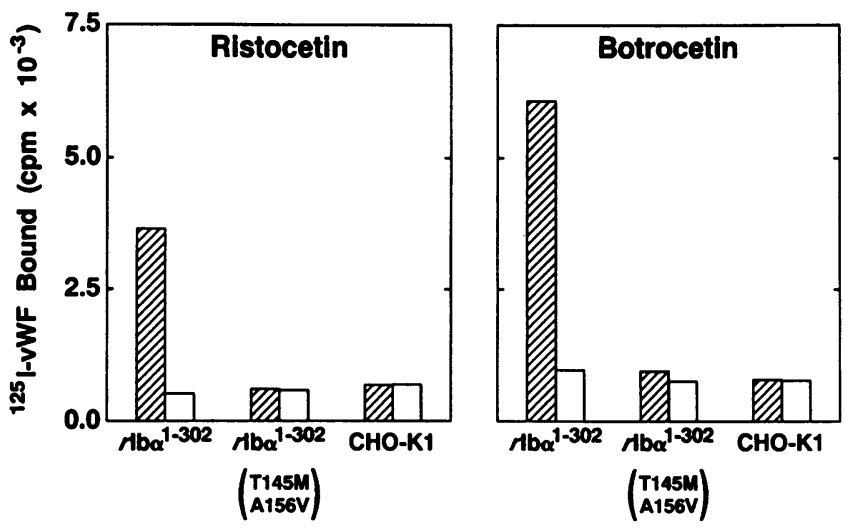

Figure 4. Interaction of ${ }^{125}$ I-labeled vWF with insolubilized recombinant GP Ib $\alpha$ fragments. Appropriate volumes (30-400 $\mu$ l) of different culture media were used to yield comparable amounts of recombinant fragments insolubilized onto the nitrocellulose membrane. After blocking of the membrane with a solution containing $1 \%$ bovine serum albumin and $1 \%$ bovine $\gamma$-globulin, the binding of ${ }^{125} \mathrm{I}$-labeled $\mathrm{vWF}(10 \mu \mathrm{g} / \mathrm{ml})$ was measured in the presence of either ristocetin $(1 \mathrm{mg} / \mathrm{ml}$; left $)$ or botrocetin $(10 \mu \mathrm{g} / \mathrm{ml}$; right $)$. The fragment designated as $r \mathrm{Ib} \alpha^{1-302}$ represents the published normal GP Ib $\alpha$ sequence (threonine at position 145 and alanine at position 156); the fragment designated as $r \mathrm{Ib} \alpha^{1-302}$ ( T145M;A156V) contains methionine at position 145 and valine at position 156, as in the Bernard-Soulier syndrome type Bolzano propositus. The sample designated as CHO-K1 represents control culture medium of nontransfected cells. Only the normal fragment supports vWF binding, both in the presence of ristocetin and botrocetin ( $\square$ ); such binding is markedly inhibited in the presence of appropriate anti-GP Ib $\alpha$ monoclonal antibodies (LJ-Ib1 and $\mathrm{LJ}-\mathrm{P} 19$, each at $100 \mu \mathrm{g} / \mathrm{ml} ; \square)$. This experiment is representative of at least four additional ones, performed with different preparations of culture media; all results were essentially identical. 


\section{Ristocetin-Induced Binding}

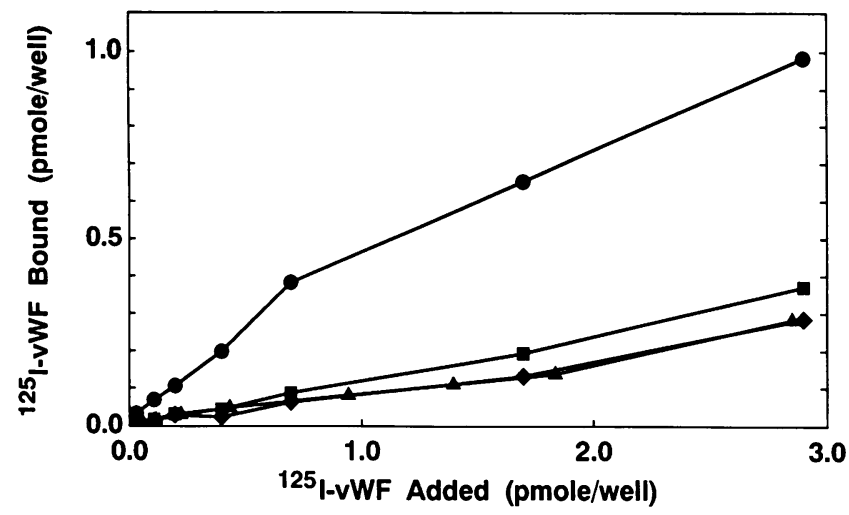

Figure 5. Dose-dependent ${ }^{125} \mathrm{I}$-vWF binding to recombinant GP Ib $\alpha$ fragments in the presence of ristocetin. Recombinant fragments were immobilized onto a nitrocellulose membrane and the latter was blocked with a solution containing $1 \%$ bovine serum albumin and $1 \%$ bovine $\gamma$-globulin, as described in the legend to Fig. 4 . Increasing concentrations of ${ }^{125}$ I-labeled vWF were then filtered through the membrane in the presence of the modulator ristocetin $(1 \mathrm{mg} / \mathrm{ml})$. Bound vWF was detected in a $\gamma$-scintillation spectrometer. Four different samples were tested in this assay: $r \mathrm{Ib} \alpha^{1-302}$ with normal sequence and the more common $\mathrm{Thr}^{145}$ dimorphic residue $(\bullet)$; $r \mathrm{Ib} \alpha^{1-302}$ with the Bernard-Soulier type Bolzano genotype, containing the $\mathrm{Thr}^{145} \rightarrow$ Met dimorphism and the Ala ${ }^{156} \rightarrow$ Val mutation $(\diamond)$; $r \mathrm{Ib} \alpha^{1-302}$ with the Ala ${ }^{156} \rightarrow$ Val mutation but the more common $\mathrm{Thr}^{145}$ dimorphic residue instead of $\mathrm{Met}^{145}(\triangle)$; culture medium of nontransfected CHO-K1 cells $(\square)$. Note that only the normal recombinant fragment supported vWF binding; presence of the Ala ${ }^{156} \rightarrow$ Val mutation, regardless of the dimorphic residue at position 145 , resulted in markedly decreased vWF binding. Three separate experiments with the normal fragment and the type Bolzano mutant gave essentially the same results.

able from that of nontransfected CHO-K1 cells; in the same assays, a recombinant fragment with normal sequence supported specific vWF binding that could be inhibited $>80 \%$ by anti-GP Ib $\alpha$ monoclonal antibodies (Fig. 4).

\section{Botrocetin-Induced Binding}

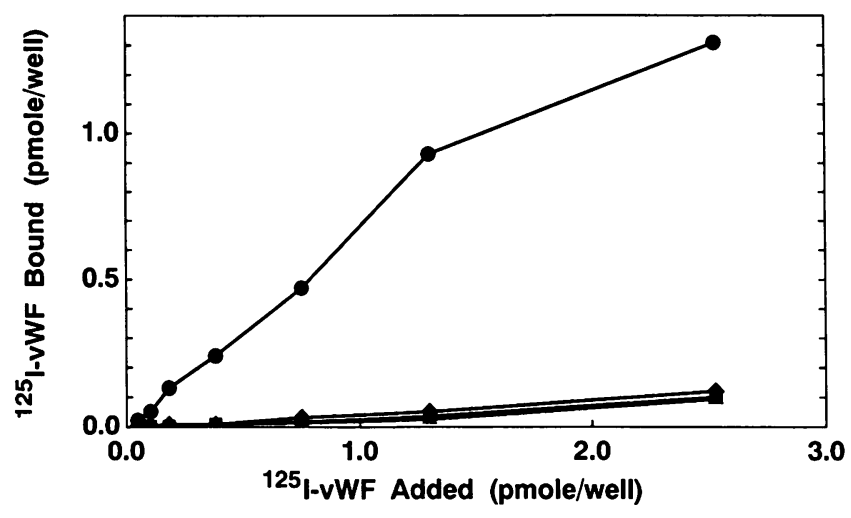

Figure 6. Dose-dependent ${ }^{125} \mathrm{I}-\mathrm{vWF}$ binding to recombinant GP Ib $\alpha$ fragments in the presence of botrocetin. The experiment was performed as described in the legend to Fig. 5, except that botrocetin ( 10 $\mu \mathrm{g} / \mathrm{ml}$ ) was used as a modulator of binding instead of ristocetin. The samples and corresponding symbols are the same as described in the legend to Fig. 5; the results obtained with botrocetin are comparable to those obtained with ristocetin.
Additional binding experiments performed with increasing ligand concentrations confirmed that the mutant fragment expressing the type Bolzano phenotype fails to interact with $\mathrm{vWF}$ both in the presence of ristocetin (Fig. 5) and botrocetin (Fig. 6 ). Moreover, a GP Ib $\alpha$ fragment containing the $\mathrm{Ala}^{156} \rightarrow \mathrm{Val}$ mutation but the more common threonine at position 145 exhibited the same loss of activity as the fragment containing Met $^{145}$ (Figs. 5 and 6), confirming that the effects of the mutation at position 156 are not influenced by the dimorphism at position 145. In this regard, therefore, vWF-binding studies and immunochemical studies (Fig. 3) gave concordant results. It should be noted that, under the experimental conditions used, the interaction of vWF with recombinant GP Ib $\alpha$ fragments is not reversible; thus, since binding is not at equilibrium, we chose not to submit the data to Scatchard-type analysis. The results obtained in this study with the normal GP Ib $\alpha$ fragment, however, are similar to those reported previously and calculated to give apparent dissociation constant comparable to that measured for vWF binding to intact GP Ib-IX complex on platelets (22).

\section{Discussion}

The pathogenesis of the Bernard-Soulier syndrome may parallel, in most instances, congenital abnormalities of other multisubunit receptor complexes, such as integrins $(31,32)$, to the extent that a defect in a single subunit prevents assembly and surface expression of the entire complex $(11,12)$. Among the reported cases of Bernard-Soulier syndrome, however, type Bolzano represents a unique example since the GP Ib-IX-V complex is present on the platelet surface, albeit with a reduced number of copies, but is dysfunctional, showing normal ability to bind $\alpha$-thrombin but defective vWF binding function (13). In previous studies (13), we suggested that the genetic defect resulting in the type Bolzano phenotype was likely to be localized in the $\alpha$-subunit of GP Ib for two reasons: ( $a$ ) vWF binding to the receptor, the function defective in platelets from the propositus, is an intrinsic property of the amino terminus of GP Ib $\alpha(21,22)$; and $(b)$ immunological characterization of the propositus' platelets demonstrated loss of the epitope recognized by the monoclonal antibody $\mathrm{LJ}-\mathrm{Ib} 1$, located within residues 1-293 of the GP Ib $\alpha$-chain (20). Indeed, we have now found that the propositus' GP Ib $\alpha$ gene contains a unique $\mathrm{Ala}^{156} \rightarrow$ Val substitution as well as two polymorphic markers, a Met ${ }^{145}$ codon instead of the more common $\mathrm{Thr}^{145}$ and coding sequence for 26 additional residues within the carbohydraterich domain. In the previous characterization of the propositus' family (13), the binding of antibody LJ-Ibl to the mother's platelets was reported to be $50 \%$ of normal, a finding consistent with the possibility of genetic heterozygosity. Indeed, it is now apparent that both parents of the propositus are obligatory carriers for the Bernard-Soulier syndrome, since they have both a mutant $\left(\mathrm{Val}^{156}\right)$ and a normal $\left(\mathrm{Ala}^{156}\right) \mathrm{GP}$ $\mathrm{Ib} \alpha$ allele. The presence of the same two polymorphic markers in the alleles containing the $\mathrm{Val}^{156}$ codon in both parents suggests that the type Bolzano phenotype is the consequence of a consanguineous mating.

Immunological characterization of recombinant fragments corresponding to the 45-kD amino-terminal domain of GP Ib $\alpha$ established a direct correlation between presence of the $\mathrm{Val}^{156}$ mutation and loss of the epitope recognized by the monoclonal antibody LJ-Ibl, the same defect exhibited by platelets from 
${ }_{1} L \times L \times \times N \times L_{8} \times \subset P X G L_{15} \times X \times L \times \times L_{22} \times X_{24}$ Leucine-rich consensus

153L S L A N N L T E L P A L L N G L N L D T176 Platelet glycoprotein Ib $\alpha$

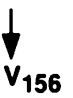

Bernard-Soulier syndrome, type Bolzano
Figure 7. Sequence alignment (single-letter designation) of the leucine-rich repeat consensus sequence and the sixth leucine-rich repeat of platelet GP Ib $\alpha$. Leucine-rich repeats form the basis for a family of

proteins containing a 24-residue motif with leucine residues at every seventh position and other conserved hydrophobic and hydrophilic residues interspersed among them (14). The variant residues of the leucine-rich consensus sequence are designated by $X$. The molecular defect resulting in the Bolzano variant of the Bernard-Soulier syndrome is an $\mathrm{Ala}^{156} \rightarrow \mathrm{Val}$ substitution and is shown at its corresponding position within a leucine-rich repeat. Sequence alignment of 138 leucine-rich repeats from 16 different proteins in the Protein Information Resource database revealed that the fourth position of the repeat, which corresponds to the identified mutation within platelet GP Ib $\alpha$, is occupied by noncharged amino acids in $65 \%$ of the repeats. $71 \%$ of the noncharged residues are Ser or Gly. None of the 138 complete leucine-rich repeats examined exhibited the hydrophobic residues Val, Leu, Ile, and Pro at the fourth position of the consensus sequence, whereas every other amino acid was represented at that position in at least one repeat.

the type Bolzano propositus (13). This amino acid substitution is not likely to affect selectively the antibody contact site but, rather, appears to have a more complex effect on the conformation of the expressed molecule. In fact, two other anti-GP Ib $\alpha$ monoclonal antibodies, each recognizing distinct epitopes sensitive to denaturation $(20,22)$, showed decreased interaction with recombinant fragments containing the $\mathrm{Val}^{156}$ mutation. Similar results have also been observed with platelets from the type Bolzano propositus, supporting the conclusion that the effects of the $\mathrm{Ala}^{156} \rightarrow$ Val mutation are essentially the same in the isolated GP Ib $\alpha$ amino-terminal fragment as they are in the GP Ib-IX-V complex on intact platelets. It is also clearly indicated by our experimental findings that the mutation at residue 156 by itself explains the abnormal immunochemical reactivity of the type Bolzano GP Ib $\alpha$ molecule, without relevant contribution by the dimorphism at position 145 . It should be remembered, however, that the Thr/Met dimorphism, per se, can independently create a new antigenic site on GP Ib $\alpha$ as well as on the expressed recombinant fragment (29).

The results of studies on the functional properties of the expressed mutant GP Ib $\alpha$ fragments support the concept that the $\mathrm{Ala}^{156} \rightarrow$ Val mutation, in addition to causing a structural abnormality resulting in the loss of conformation-sensitive epitopes, is also responsible for decreased vWF binding. Two exogenous modulators were used in these assays, ristocetin and botrocetin, as commonly done to measure the binding of native soluble vWF to platelets. These modulators may mimic events that occur at a site of vascular injury where soluble vWF becomes adsorbed onto exposed subendothelial structures and then promotes the attachment of platelets through the GP IbIX-V complex (33). Botrocetin forms a bimolecular complex with vWF that, in turn, binds specifically to GP Ib $\alpha$ (27); ristocetin acts in a less well-defined manner, but is thought to require interaction with both vWF and the platelet membrane in order to promote vWF binding to GP Ib $\alpha$ (34). It has been demonstrated that changes in GP Ib $\alpha$ conformation induced by reduction of disulfide bonds have different effects on vWF binding mediated by either ristocetin or botrocetin (21), indicating that each modulator elicits a distinct mode of ligand-receptor interaction. The correspondence between the effects of ristocetin and botrocetin, on one side, and the mechanisms physiologically relevant for vWF binding to platelets in vivo remains to be clarified. Nevertheless, studies in patients with von Willebrand disease have provided examples that support the use of both ristocetin (35) and botrocetin (36) for reproducing phenotypic abnormalities of the vWF-GP Ib interac- tion. This suggests that neither modulator by itself may be sufficient to probe the vWF binding function of GP Ib $\alpha$ in its complexity and that their concurrent use may be necessary to obtain useful information in this regard. In the present studies, the functional consequences of the $\mathrm{Ala}^{156} \rightarrow$ Val mutation could be demonstrated using both ristocetin and botrocetin as modulators of vWF binding to immobilized recombinant GP Ib $\alpha$ fragments, providing strong evidence that the identified mutation represents, indeed, the molecular basis of the type Bolzano variant of Bernard-Soulier syndrome. Moreover, it is apparent from all our results that the structural and functional effects of the Ala ${ }^{156} \rightarrow$ Val mutation are independent of the $\mathrm{Thr} /$ Met dimorphism at residue 145.

The identification of the effects caused by the $\mathrm{Ala}^{156} \rightarrow \mathrm{Val}$ mutation in GP Ib $\alpha$ may have implications for understanding the structure and function of other proteins. Residue 156 is part of a conserved repetitive motif originally described in leucine-rich $\alpha_{2}$-glycoprotein (37) and present in a growing list of diverse molecules with functions related to cell-cell, cell-protein, or protein-protein interactions (14). All four subunits of the GP Ib-IX-V complex contain this motif characterized by a conserved spacing of leucine residues within a 24-amino acid sequence (4-8). There are similarities and dissimilarities between the leucine-rich repeats and the well-characterized leucine-zipper motif (14). The most striking similarity is the predominance of leucine residues and their similar spacing at every seventh position (Fig. 7); however, the leucine-rich repeats have a high content of proline residues that are likely to interfere with the formation of the regular coiled-coil structure that serves as the backbone for the leucine-zipper (38). The three-dimensional conformation of leucine-rich repeats is unknown, but it has been proposed that they form amphipathic $\beta$ sheets (39). Perhaps, the local increase in hydrophobicity caused by the Ala ${ }^{156} \rightarrow$ Val mutation may alter the amphipathic structure and interfere with the surface orientation of residues involved in interactions that are essential for the structural and functional integrity of GP Ib $\alpha$. It is noteworthy that in $>100$ homologous sequences present in the protein database, the position corresponding to residue 156 in GP Ib $\alpha$ is predominantly occupied by polar residues; thus far, valine, leucine, isoleucine, and proline have never been found in that position (Fig. 7). It has been proposed that leucine-rich repeats may be involved in protein-membrane and protein-protein interactions (37, 39-41). With regard to the GP Ib-IX-V complex, however, we have now demonstrated that they affect the activity of the vWF binding site even when expressed in an 
isolated soluble fragment of GP Ib $\alpha$. Thus, such function does not require interactions with the platelet membrane; moreover, it is clearly intrinsic to the $\alpha$-chain and independent of association with homologous sequences in the other components of the receptor complex.

Previous results obtained with synthetic peptides (42) and recombinant fragments (22) indicate that a domain relevant for vWF-binding function is located between residues 221 and 318 of GP Ib $\alpha$, with a predominant role for a cluster of negatively charged residues between positions 251 and 279 (Fig. 1). The leucine-rich repeats may provide the conformation necessary for the function of this site, e.g., affecting the orientation of charged residues, without necessarily having a direct participation in establishing contact with the ligand. Such structural effects may be achieved through self-interactions of the homologous leucine-rich sequences, a function that may be regulated through the number of repeats present in a given molecule. That the Ala ${ }^{156} \rightarrow$ Val substitution may indeed alter the conformation of the amino terminal domain of GP Ib $\alpha$ is suggested by the evidence that the type Bolzano mutant has not only an abnormal interaction with vWF but also markedly decreased reactivity with three different monoclonal antibodies each recognizing distinct and nonoverlapping epitopes $(20,22$, 42). Appropriate conformation maintained by the leucine-rich repeat region in the extracytoplasmic domain may also influence the linkage of the intracytoplasmic tail of GP Ib $\alpha$ to the cytoskeleton (43), so that the Ala ${ }^{156} \rightarrow$ Val mutation may be responsible for both the ligand binding defect and the aberrant morphology of giant platelets in the type Bolzano variant.

\section{Acknowledgements}

We acknowledge the Sam and Rose Stein Trust Fund in the Department of Molecular and Experimental Medicine at The Scripps Research Institute for financial support to the DNA core facility.

This work was supported by grant HL-42846 from the National Institutes of Health. Additional support for the General Clinical Research Center (National Institutes of Health grant RR-0833) is also acknowledged. This is manuscript 7484-MEM/CVB from the Scripps Research Institute.

\section{References}

1. Caen, J. P., A. T. Nurden, C. Jeanneau, H. Michel, G. Tobelem, S. LevyToledano, Y. Sultan, F. Valensi, and J. Bernard. 1976. Bernard-Soulier syndrome: a new platelet glycoprotein abnormality. Its relationship with platelet adhesion to subendothelium and with the factor VIII von Willebrand protein. $J$. Lab. Clin. Med. 87:586-596.

2. Nurden, A. T., and J. P. Caen. 1975. Specific roles for platelet surface glycoproteins in platelet function. Nature (Lond.). 255:720-722.

3. Ruggeri, Z. M. 1991. The platelet glycoprotein Ib-IX Complex. In Progress in Hemostasis and Thrombosis. B. S. Coller, editor. W. B. Saunders Company, Philadelphia. 35-68.

4. Titani, K., K. Takio, M. Handa, and Z. M. Ruggeri. 1987. Amino acid sequence of the von Willebrand factor-binding domain of platelet membrane glycoprotein Ib. Proc. Natl. Acad. Sci. USA. 84:5610-5614.

5. Lopez, J. A., D. W. Chung, K. Fujikawa, F. S. Hagen, T. Papayannopoulou, and G. J. Roth. 1987. Cloning of the alpha chain of human platelet glycoprotein Ib: a transmembrane protein with homology to leucine-rich alpha2-glycoprotein. Proc. Natl. Acad. Sci. USA. 84:5615-5619.

6. Lopez, J. A., D. W. Chung, K. Fujikawa, F. S. Hagen, E. W. Davie, and G. J. Roth. 1988. The alpha and beta chains of human platelet glycoprotein Ib are both transmembrane proteins containing a leucine-rich amino acid sequence. Proc. Natl. Acad. Sci. USA. 85:2135-2139.

7. Hickey, M. J., S. A. Williams, and G. J. Roth. 1989. Human platelet glycoprotein IX: an adhesive prototype of leucine-rich glycoproteins with flankcenter-flank structures. Proc. Natl. Acad. Sci. USA. 86:6773-6777.
8. Shimomura, T., K. Fujimura, S. Maehama, M. Takemoto, K. Oda, T. Fujimoto, R. Oyama, M. Suzuki, K. Ichihara-Tanaka, K. Titani, et al. 1990. Rapid purification and characterization of human platelet glycoprotein V: the amino acid sequence contains leucine-rich repetitive modules as in glycoprotein Ib. Blood. 75:2349-2356.

9. Modderman, P. W., L. G. Admiraal, A. Sonnenberg, and A. E. G. Kr. von dem Borne. 1992. Glycoproteins V and Ib-IX form a noncovalent complex in the platelet membrane. J. Biol. Chem. 267:364-369.

10. Berndt, M. C., C. Gregory, B. H. Chong, H. Zola, and P. A. Castaldi. 1983. Additional glycoprotein defects in Bernard-Soulier's syndrome: confirmation of genetic basis by parental analysis. Blood. 62:800-807.

11. Ware, J., S. R. Russell, V. Vicente, R. E. Scharf, A. Tomer, R. McMillan, and Z. M. Ruggeri. 1990. Nonsense mutation in the glycoprotein Ibalpha coding sequence associated with Bernard-Soulier syndrome. Proc. Natl. Acad. Sci. USA. 87:2026-2030.

12. Lopez, J. A., B. Leung, C. C. Reynolds, C. Q. Li, and J. E. B. Fox. 1992. Efficient plasma membrane expression of a functional platelet glycoprotein Ib-IX complex requires the presence of its three subunits. J. Biol. Chem. 267:1285112859.

13. De Marco, L., M. Mazzucato, F. Fabris, D. De Roia, P. Coser, A. Girolami, V. Vicente, and Z. M. Ruggeri. 1990. Variant Bernard-Soulier syndrome type Bolzano: a congenital bleeding disorder due to a structural and functional abnormality of the platelet glycoprotein Ib-IX complex. J. Clin. Invest. 86:25-31.

14. Roth, G. J. 1991. Developing relationships: arterial platelet adhesion, glycoprotein Ib, and leucine-rich glycoproteins. Blood. 77:5-19.

15. De Marco, L., F. Fabris, A. Casonato, P. Fabris, M. G. Del Ben, A. Barbato, and A. Girolami. 1986. Bernard-Soulier syndrome: diagnosis by an ELISA method using monoclonal antibodies in 2 new unrelated patients. Acta Haematol. 75:203-208.

16. Blin, N., and D. W. Stafford. 1976. A general method for isolation of high molecular weight DNA from eukaryocytes. Nucleic Acid Res. 3:2303-2308.

17. Sambrook, J., E. F. Fritsch, and T. Maniatis. 1989. Molecular Cloning: A Laboratory Manual. Cold Spring Harbor Laboratory Press, Cold Spring Harbor, NY.

18. Saiki, R. K., D. H. Gelfand, S. Stoffel, S. J. Scharf, R. Higuchi, G. T. Horn, K. B. Mullis, and H. A. Erlich. 1988. Primer-directed enzymatic amplification of DNA with a thermostable DNA polymerase. Science (Wash. DC). 239:487-491.

19. Wenger, R. H., N. Kieffer, A. N. Wicki, and K. J. Clemetson. 1988. Structure of the human blood platelet membrane glycoprotein Ib alpha gene. Biochem. Biophys. Res. Commun. 156:389-395.

20. Handa, M., K. Titani, L. Z. Holland, J. R. Roberts, and Z. M. Ruggeri. 1986. The von Willebrand factor-binding domain of platelet membrane glycoprotein Ib. Characterization by monoclonal antibodies and partial amino acid sequence analysis of proteolytic fragments. J. Biol. Chem. 261:12579-12585.

21. Vicente, V., P. J. Kostel, and Z. M. Ruggeri. 1988. Isolation and functional characterization of the von Willebrand factor-binding domain located between residues His( 1)-Arg (293) of the alpha-chain of glycoprotein Ib. J. Biol. Chem. 263:18473-18479.

22. Murata, M., J. Ware, and Z. M. Ruggeri. 1991. Site-directed mutagenesis of a soluble recombinant fragment of platelet glycoprotein Ib $\alpha$ demonstrating negatively charged residues involved in von Willebrand factor binding. J. Biol. Chem. 266:15474-15480.

23. Seed, B. 1987. An LFA-3 cDNA encodes a phospholipid-linked membrane protein homologous to its receptor CD2. Nature (Lond.). 329:840-842.

24. Kunkel, T. A., J. D. Roberts, and R. A. Zakour. 1987. Rapid and efficient site-specific mutagenesis without phenotypic selection. Methods Enzymol. 154:367-383.

25. Chen, C., and H. Okayama. 1987. High-efficiency transformation of mammalian cells by plasmid DNA. Mol. Cell. Biol. 7:2745-2752.

26. Fujimura, Y., K. Titani, Y. Usami, M. Suzuki, R. Oyama, T. Matsui, H. Fukui, M. Sugimoto, and Z. M. Ruggeri. 1991. Isolation and chemical characterization of two structurally and functionally distinct forms of botrocetin, the platelet coagglutinin isolated from the venom of Bothrops jararaca. Biochemistry. 30:1957-1964.

27. Sugimoto, M., H. Mohri, R. A. McClintock, and Z. M. Ruggeri. 1991. Identification of discontinuous von Willebrand factor sequences involved in complex formation with Botrocetin: a model for the regulation of von Willebrand factor binding to platelet glycoprotein Ib. J. Biol. Chem. 266:18172-18178.

28. Kuijpers, R. W. A. M., N. M. Faber, H. Th. M. Cuypers, W. H. Ouwehand, and A. E. G. Kr. von dem Borne. 1992. NH2-terminal globular domain of human platelet glycoprotein Ib alpha has a methionine 145/threonine 145 amino acid polymorphism, which is associated with HPA-2 (Ko) alloantigens. J. Clin. Invest. 89:381-384.

29. Murata, M., K. Furihata, F. Ishida, S. R. Russell, J. Ware, and Z. M. Ruggeri. 1992. Genetic and structural characterization of an amino acid dimorphism in glycoprotein Ib $\alpha$ involved in platelet transfusion refratoriness. Blood. 79:3086-3090.

30. Lopez, J. A., E. H. Ludwig, and B. J. McCarthy. 1992. Polymorphism of human glycoprotein Ib $\alpha$ results from a variable number of tandem repeats of a 
13-amino acid sequence in the mucin-like macroglycopeptide region. J. Biol. Chem. 267:10055-10061.

31. Kishimoto, T. K., N. Hollander, T. M. Roberts, D. C. Anderson, and T. A. Springer. 1987. Heterogeneous mutations in the beta subunit common to the LFA-1, Mac-1, and p150,95 glycoproteins cause leukocyte adhesion deficiency. Cell. 50:193-202.

32. O'Toole, T. E., J. C. Loftus, E. F. Plow, A. A. Glass, J. R. Harper, and M. H. Ginsberg. 1989. Efficient surface expression of platelet GP IIb-IIIa requires both subunits. Blood. 74:14-18.

33. Ruggeri, Z. M., and J. Ware. 1992. The structure and function of von Willebrand factor. Thromb. Haemostasis. 67:594-599.

34. Scott, J. P., R. R. Montgomery, and G. S. Retzinger. 1991. Dimeric ristocetin flocculates proteins, binds to platelets, and mediates von Willebrand factor-dependent agglutination of platelets. J. Biol. Chem. 266:8149-8155.

35. Rabinowitz, I., E. A. Tuley, D. J. Mancuso, A. M. Randi, B. G. Firkin, M. A. Howard, and J. E. Sadler. 1992. von Willebrand disease type B: a missense mutation selectively abolishes ristocetin-induced von Willebrand factor binding to platelet glycoprotein Ib. Proc. Natl. Acad. Sci. USA. 89:9846-9849.

36. Liu, X, J. P. Scott, D. J. Mancuso, P. A. Kroner, P. J. Newman, E. A. Vokac, and R. R. Montgomery. 1992. Substitution of Pro or Glu for Arg ${ }^{578}$ of von Willebrand factor (vWF) differentially affects vWF interaction with platelets. Blood. 80(Suppl. I):368a. (Abstr.)
37. Takahashi, N., Y. Takahashi, and F. W. Putnam. 1985. Periodicity of leucine and tandem repetition of a 24-amino acid segment in the primary structure of leucine-rich alpha 2-glycoprotein of human serum. Proc. Natl. Acad. Sci. USA. 82:1906-1910.

38. Landschulz, W. H., P. F. Johnson, and S. L. McKnight. 1988. The leucine zipper: a hypothetical structure common to a new class of DNA binding proteins. Science (Wash. DC). 240:1759-1764.

39. Reinke, R., D. E. Krantz, D. Yen, and S. L. Zipursky. 1988. Chaoptin, a cell surface glycoprotein required for drosophila photoreceptor cell morphogenesis, contains a repeat motif found in yeast and human. Cell. 52:291-301.

40. Hashimoto, C., K. L. Hudson, and K. V. Anderson. 1988. The Toll gene of Drosophila, required for dorsal-ventral embryonic polarity, appears to encode a transmembrane protein. Cell. 52:269-279.

41. Tan, F., D. K. Weerasinghe, R. A. Skidgel, H. Tamei, R. K. Kaul, I. G. Roninson, J. W. Schilling, and E. G. Erdos. 1990. The deduced protein sequence of the human carboxypeptidase $\mathbf{N}$ high molecular weight subunit reveals the presence of leucine-rich tandem repeats. J. Biol. Chem. 265:13-19.

42. Vicente, V., R. A. Houghten, and Z. M. Ruggeri. 1990. Identification of a site in the alpha chain of platelet glycoprotein Ib that participates in von Willebrand factor binding. J. Biol. Chem. 265:274-280.

43. Fox, J. E. B. 1985. Linkage of a membrane skeleton to integral membrane glycoprotein in human platelets. Identification of one of the glycoproteins as glycoprotein Ib. J. Clin. Invest. 76:1673-1683. 